\title{
Efeito da safra vitícola na composição da uva, do mosto e do vinho Isabel da Serra Gaúcha, Brasil
}

\author{
Effect of the vintage on the composition of the Isabel grape, must and wine \\ from Serra Gaúcha, Brazil
}

Luiz Antenor Rizzon ${ }^{1}$ Alberto Miele ${ }^{2}$

\section{RESUMO}

Entre os fatores que interferem na composição $e$ na qualidade do vinho, destaca-se a safra vitícola, com suas variações climáticas. Com este objetivo, avaliou-se o efeito das safras de 1999, 2000 e 2001 na composição da uva, do mosto e do vinho Isabel da Serra Gaúcha. Nesse sentido, foram selecionados vinte e dois produtores de uva Isabel de onze municípios dessa região. Por ocasião da maturação, para as avaliações da uva e do mosto e a elaboração das microvinificações, foram colhidos $60 \mathrm{~kg}$ de uva de cada viticultor. A safra vitícola interferiu significativamente no peso do cacho e da baga, mas não alterou a relação peso da ráquis/ peso do cacho. No mosto, observaram-se diferenças em todas as variáveis, exceto para a relação ${ }^{\circ}$ Brix/acidez total. No vinho, teve efeito na maior parte das variáveis avaliadas, com exceção aos cátions $K, \mathrm{Mn}, \mathrm{Cu}$ e Rb. Em geral, a safra de 1999 foi a melhor, pois apresentou parâmetros mais adequados de acidez total, extrato seco, extrato seco reduzido, alcalinidade das cinzas, taninos, antocianinas e glicerol, variáveis essas que determinam a estrutura e a cor dos vinhos, importantes fatores para sua qualidade.

Palavras-chave: safra vitícola, composição química, fatores climáticos, Vitis Iabrusca.

\section{ABSTRACT}

Variation of the climatic conditions among years is one of the most important factors having influence on wine composition and quality. This work evaluated the effect of the 1999, 2000, and 2001 vintages of the Isabel grape, must, and wine composition from Serra Gaúcha, Brazil. In this way, twenty-two grape growers from 11 communities of this region were taken. From each grower, $60 \mathrm{~kg}$ of ripened grapes were sampled from which evaluations on grape and must were performed and microvinifications were made. Results showed that the vintage had a significant effect on cluster and berry weight, but there was no effect on stem/cluster weight ratio. In the same way, there was differences on the majority of the variables of the must of Isabel studied, exception to the ${ }^{\circ} \mathrm{Brix} /$ total acidity ratio. It also had effect on the majority of the variables of the wine, exception to the $K, M n, C u$, and $R b$ cations. In general, the 1999 vintage was better, because it showed more adequate parameters for total acidity, dry extract, reduced dry extract, alkalinity of ashes, tannins, anthocyanins, and glycerol, variables that determine wine structure and color, important factors for wine quality.

Key words: vintage, chemical composition, climatic factors, Vitis labrusca.

\section{INTRODUÇÃO}

O vinho é uma bebida de composição complexa, devido às transformações biológicas, químicas, físicas e enzimáticas que ocorrem em seu processamento (ZOECKLEIN et al., 1994). Entre os fatores naturais, a safra vitícola exerce influência preponderante na qualidade da uva e, conseqüentemente, do vinho. Cada safra apresenta peculiaridades específicas. Assim, para uma mesma cultivar, as condições climáticas do período de maturação da uva podem antecipar ou retardar a colheita, influir nas concentrações de açúcar e de ácidos orgânicos, no teor de compostos voláteis e de compostos fenólicos da uva (CHAMPAGNOL, 1984). Nas safras em que a maturação ocorre em período mais ensolarado e seco, a uva é mais doce e menos ácida. Na Serra Gaúcha, nas últimas décadas, as safras de 1979, 1986, 1991, 1999, 2002, 2004 e 2005 se distinguiram

${ }^{1}$ Embrapa Uva e Vinho, Caixa Postal 130, 95700-000, Bento Gonçalves, RS, Brasil. E-mail: rizzon@cnpuv.embrapa.br. Autor para correspondência.

${ }^{2}$ Embrapa Uva e Vinho, Bento Gonçalves, RS, Brasil. E-mail: miele@cnpuv.embrapa.br 
pela qualidade, pois a maturação ocorreu em período mais seco (RIZZON, 1986; MANDELLI, 1999, 2000 e 2001).

Em relação às cultivares difundidas na Serra Gaúcha, cerca de $85 \%$ da superfície é ocupada por videiras do grupo das americanas e híbridas, com predominância da Isabel (Vitis labrusca), que representa aproximadamente $45 \%$ da área plantada. Em geral, são cultivares rústicas e mais produtivas que as pertencentes à espécie Vitis vinifera. Devido ao volume de produção e à sua importância econômica, realizouse o presente estudo para avaliar o efeito da safra vitícola nas características da uva e na composição do mosto e do vinho Isabel da Serra Gaúcha.

\section{MATERIAL E MÉTODOS}

Inicialmente, foram identificados e selecionados dois produtores de uva Isabel de cada um dos seguintes municípios da Serra Gaúcha: Antônio Prado, Bento Gonçalves, Caxias do Sul, Farroupilha, Flores da Cunha, Garibaldi, Monte Belo do Sul, Nova Pádua, Nova Roma do Sul, São Marcos e Veranópolis.

Por ocasião da maturação, foram colhidos $60 \mathrm{~kg}$ de uva de cada viticultor, amostra essa representativa do vinhedo. A uva foi transportada para a Embrapa Uva e Vinho em caixas de plástico de 20kg de capacidade, onde foram determinados os pesos do cacho e da baga e a relação peso da ráquis/peso do cacho. Após, esmagou-se a uva em uma desengaçadeira-esmagadeira e separaram-se amostras do mosto para a determinação da densidade, sólidos solúveis totais ( ${ }^{\circ}$ Brix), acidez total e volátil, $\mathrm{pH}$, potencial alcoólico, prolina e nitrogênio amoniacal. A relação ${ }^{\circ}$ Brix/ acidez total foi obtida pela divisão do ${ }^{\circ}$ Brix pela acidez total expressa em g $100 \mathrm{~g}^{-1}$ de ácido tartárico (ZOECKLEIN et al., 1994). O mosto foi colocado em três recipientes de 20L de capacidade, adicionando-se dióxido de enxofre na dose de $50 \mathrm{mg} \mathrm{L}^{-1}$ e levedura seca selecionada (Saccharomyces cerevisiae) na proporção de $0,20 \mathrm{~g} \mathrm{~L}^{-1}$. A seguir, foram colocadas válvulas de Müller nos recipientes de vidro para permitir a saída de dióxido de carbono formado durante a fermentação alcoólica. Os recipientes foram colocados em uma sala climatizada a $25^{\circ} \mathrm{C}$. O período de maceração foi de cinco dias, com uma homogeneização diária. Depois da descuba, os vinhos foram armazenados em dois recipientes, onde permaneceram até completar as fermentações alcoólica e malolática. A seguir, foi efetuada uma trasfega para separação das borras, adicionando-se mais $60 \mathrm{mg} \mathrm{L}^{-1}$ de dióxido de enxofre. Os vinhos foram então uniformizados em um único recipiente, resfriados a $-2^{\circ} \mathrm{C}$ para estabilização do tartarato ácido de potássio, filtrados, engarrafados e analisados quanto às variáveis físico-químicas (densidade, álcool, acidez total e volátil, $\mathrm{pH}$, extrato seco, açúcares redutores, extrato seco reduzido, relação álcool em peso/extrato seco reduzido, cinzas, alcalinidade das cinzas, DO 420nm, DO 520nm, intensidade de cor, coloração e dióxido de enxofre total). Essas análises foram realizadas utilizando-se metodologia descrita por ZOECKLEIN et al. (1994).Além dessas variáveis, avaliaram-se, ainda, os polifenóis totais, os taninos e as antocianinas segundo RIBÉREAU-GAYON \& STONESTREET $(1965,1966)$; os cátions Ca, Mg, Mn, Fe, Cu e Zn, determinados por absorção atômica, e o K, Na e Li, por emissão de chama (PERKIN-ELMER, 2000); o P foi determinado por colorimetria, utilizando-se o molibdato de amônio (TEDESCO et al., 1995).

O delineamento experimental utilizado foi inteiramente casualizado, considerando as safras como tratamentos e os viticultores como repetições. Os resultados obtidos foram submetidos à análise de variância e ao teste de Tukey para comparação das médias a 5\% de probabilidade de erro.

\section{RESULTADOS E DISCUSSÃO}

A influência da safra vitícola nas características do cacho da uva Isabel está indicada na tabela 1 . O peso do cacho de uma cultivar de videira está relacionado com o número e o volume da baga (CHAMPAGNOL, 1984). Tradicionalmente, a uva Isabel se caracteriza por ter o cacho relativamente pequeno, com um número reduzido de bagas. No presente estudo, de modo geral, o peso médio do cacho está relacionado ao peso da baga e é similar ao valor indicado para a Serra Gaúcha (RIZZON et al., 2000). A menor precipitação pluviométrica que ocorreu no ciclo vegetativo de 1998-1999 (MANDELLI, 1999) foi um dos principais fatores que determinaram a diminuição do peso médio do cacho na safra de 1999. Não se constatou efeito significativo do ano na relação peso da ráquis/ peso do cacho.

Com relação ao mosto da uva, observou-se influência da safra vitícola em todas as variáveis físicoquímicas avaliadas (Tabela 2), exceto para a relação 'Brix/acidez total. O mosto, nas safras de 1999 e 2000, apresentou teores mais elevados das variáveis que caracterizam o açúcar - densidade, ${ }^{\circ}$ Brix e potencial alcoólico - e a acidez total. Entretanto, não houve efeito significativo sobre a relação ${ }^{\circ}$ Brix/acidez total. A maturação da uva em 1999 ocorreu com tempo mais seco (MANDELLI, 1999), fator que a favoreceu. Como 
Tabela 1 - Efeito da safra vitícola nas características do cacho da uva Isabel na Serra Gaúcha.

\begin{tabular}{|c|c|c|c|c|c|c|}
\hline \multirow{2}{*}{ Variável } & \multicolumn{3}{|c|}{ Safra } & \multirow{2}{*}{ Média } & \multirow{2}{*}{ CV (\%) } & \multirow{2}{*}{ Prob $>F$} \\
\hline & 1999 & 2000 & 2001 & & & \\
\hline Peso do cacho (g) & $129,0 \mathrm{~b}$ & $135,5 \mathrm{~b}$ & $147,0 \mathrm{a}$ & 137,2 & 11,24 & 0,00150 \\
\hline Peso da baga (g) & $2,98 \mathrm{ab}$ & $2,94 \mathrm{~b}$ & 3,11 a & 3,01 & 7,08 & 0,02323 \\
\hline $\begin{array}{l}\text { Peso da ráquis/ } \\
\text { Peso do cacho (\%) }\end{array}$ & $2,26 \mathrm{a}$ & 2,49 a & 2,62 a & 2,46 & 22,62 & 0,09960 \\
\hline
\end{tabular}

Médias seguidas por letras distintas na linha diferem entre si pelo teste de Tukey a 5\% de probabilidade de erro.

o açúcar é o constituinte que tem maior participação na densidade e no ${ }^{\circ}$ Brix, as variações dessas duas variáveis estão sempre bem correlacionadas.

$\mathrm{O}$ pH foi mais elevado em 2001, ano que se caracterizou pelo excesso hídrico na fase de maturação e de colheita da uva e pela elevada produtividade dos vinhedos. Logo, a absorção excessiva de água pelas raízes da videira provocou maior absorção de K. Isso ocasionou a salificação do ácido tartárico, a qual provocou a elevação do $\mathrm{pH}$ e a diminuição da acidez total (RIZZON \& MIELE, 2002). A acidez volátil, mesmo que os valores tenham sido baixos, foi mais elevada em 2001, devido provavelmente ao estado sanitário da uva. A acidez volátil do mosto, juntamente com os teores de ácido glicônico e de glicerol, são indicativos da qualidade sanitária da uva para vinificação. Concentrações baixas desses compostos indicam uva com menor ataque de podridão cinzenta da uva (MENEGUZZO et al., 1999).

Quanto à prolina, o teor mais elevado em 1999 é um indicativo de que a uva alcançou melhor maturação nessa safra. Além disso, apesar de a cv. Isabel ser uma Vitis labrusca e ter baixa concentração de prolina (MIELE et al., 1990), é um aminoácido indicador de estresse hídrico (COOMBE \& MONK, 1979), o que está de acordo com a menor precipitação pluviométrica dessa safra.

O nitrogênio amoniacal representa a porção do nitrogênio prontamente assimilável pela levedura na fermentação alcoólica. Durante a maturação da uva, observa-se uma redução do nitrogênio amoniacal e, geralmente, nas safras em que a uva alcança um estágio mais avançado de maturação, seu teor é mais baixo (CHAMPAGNOL, 1984). Nesse sentido, a safra de 2000 se destacou por apresentar menor teor de nitrogênio amoniacal, embora não tenha apresentado diferença significativa com a de 1999.

Os resultados das análises clássicas do vinho Isabel das safras de 1999, 2000 e 2001 estão indicados na tabela 3. O vinho da safra de 1999 se caracterizou por apresentar valores de acidez total, extrato seco, extrato seco reduzido, alcalinidade das cinzas, taninos, antocianinas, DO 420, DO 520, intensidade de cor e glicerol mais elevados. Esses valores determinam maior estrutura e intensidade de cor nos vinhos dessa safra, fatores indicativos de qualidade. Entretanto, não diferiu significativamente de 2000 no que se relaciona ao álcool e à prolina, e de

Tabela 2 - Efeito da safra vitícola nas características analíticas do mosto da uva Isabel na Serra Gaúcha.

\begin{tabular}{|c|c|c|c|c|c|c|}
\hline \multirow{2}{*}{ Variável } & \multicolumn{3}{|c|}{ Safra } & \multirow{2}{*}{ Média } & \multirow{2}{*}{$\mathrm{CV}(\%)$} & \multirow{2}{*}{ Prob $>F$} \\
\hline & 1999 & 2000 & 2001 & & & \\
\hline Densidade a $20^{\circ} \mathrm{C}\left(\mathrm{g} \mathrm{mL}^{-1}\right)$ & $1,0742 \mathrm{a}$ & $1,0729 \mathrm{a}$ & $1,0690 \mathrm{~b}$ & 1,0720 & 0,46 & 0,00297 \\
\hline Sólidos solúveis totais ( ${ }^{\circ}$ Brix) & 17,7 a & $17,3 \mathrm{ab}$ & $16,6 \mathrm{~b}$ & 17,2 & 6,60 & 0,00753 \\
\hline Acidez total (meq $\mathrm{L}^{-1}$ ) & $50,5 \mathrm{a}$ & $45,8 a b$ & $42,9 \mathrm{~b}$ & 46,4 & 18,58 & 0,01685 \\
\hline Acidez volátil (meq $\mathrm{L}^{-1}$ ) & $1,5 \mathrm{~b}$ & $1,1 \mathrm{c}$ & 1,9 a & 1,5 & 22,12 & 0,00001 \\
\hline $\mathrm{pH}$ & $3,22 \mathrm{c}$ & $3,30 \mathrm{~b}$ & 3,40 a & 3,31 & 2,45 & 0,00001 \\
\hline Relação ${ }^{\circ}$ Brix/Acidez total & 47,8 a & 51,7 a & 53,3 a & 50,9 & 19,37 & 0,17634 \\
\hline Potencial alcoólico (\% v/v) & 9,85 a & 9,69 a & $9,01 \mathrm{~b}$ & 9,52 & 8,15 & 0,00210 \\
\hline Prolina (mg L $\left.{ }^{-1}\right)$ & 28,6 a & $12,4 \mathrm{c}$ & $21,3 \mathrm{~b}$ & 20,8 & 30,91 & 0,00001 \\
\hline Nitrogênio amoniacal $\left(\mathrm{mg} \mathrm{L}^{-1}\right)$ & $31,0 a b$ & $27,9 \mathrm{~b}$ & 36,4 a & 31,8 & 31,32 & 0,02229 \\
\hline
\end{tabular}

Médias seguidas por letras distintas na linha diferem entre si pelo teste de Tukey a 5\% de probabilidade de erro.

Ciência Rural, v.36, n.3, mai-jun, 2006. 
Tabela 3 - Efeito da safra vitícola nas características analíticas do vinho Isabel na Serra Gaúcha.

\begin{tabular}{|c|c|c|c|c|c|c|}
\hline \multirow{2}{*}{ Variável } & \multicolumn{3}{|c|}{ Safra } & \multirow{2}{*}{ Média } & \multirow{2}{*}{ CV (\%) } & \multirow{2}{*}{ Prob $>$ F. } \\
\hline & 1999 & 2000 & 2001 & & & \\
\hline Densidade a $20^{\circ} \mathrm{C}\left(\mathrm{g} \mathrm{mL}^{-1}\right)$ & 0,9969 a & $0,9962 \mathrm{~b}$ & 0,9973 a & 0,9968 & 0,08 & 0,00014 \\
\hline Álcool (\% v/v) & 9,77 a & $9,52 \mathrm{a}$ & $8,71 \mathrm{~b}$ & 9,33 & 8,00 & 0,00014 \\
\hline Acidez total (meq L $\mathrm{L}^{-1}$ ) & 107,5 a & $91,4 \mathrm{~b}$ & $90,9 \mathrm{~b}$ & 96,6 & 8,21 & 0,00001 \\
\hline Acidez volátil (meq $\mathrm{L}^{-1}$ ) & $6,5 \mathrm{c}$ & $7,8 \mathrm{~b}$ & 8,9 a & 7,7 & 15,90 & 0,00001 \\
\hline $\mathrm{pH}$ & $3,17 \mathrm{c}$ & $3,24 b$ & 3,30 a & 3,24 & 2,51 & 0,00003 \\
\hline Extrato seco $\left(\mathrm{g} \mathrm{L}^{-1}\right)$ & $22,5 \mathrm{a}$ & $19,1 \mathrm{~b}$ & $19,0 \mathrm{~b}$ & 20,2 & 7,73 & 0,00001 \\
\hline Açúcares redutores $\left(\mathrm{g} \mathrm{L}^{-1}\right)$ & $2,14 b$ & $2,40 \mathrm{a}$ & $2,12 \mathrm{~b}$ & 2,22 & 13,07 & 0,00378 \\
\hline Extrato seco reduzido ( $\mathrm{g} \mathrm{L}^{-1}$ ) & $21,4 \mathrm{a}$ & $17,7 \mathrm{~b}$ & $18,0 \mathrm{~b}$ & 19,0 & 7,50 & 0,00001 \\
\hline Relação álcool em peso / Extrato seco reduzido & 3,65 c & $4,32 \mathrm{a}$ & $3,92 \mathrm{~b}$ & 3,96 & 6,93 & 0,00001 \\
\hline Cinzas $\left(\mathrm{g} \mathrm{L}^{-1}\right)$ & $2,01 \mathrm{a}$ & $1,87 \mathrm{~b}$ & $1,98 \mathrm{ab}$ & 1,95 & 9,73 & 0,03424 \\
\hline Alcalinidade das cinzas ( $\mathrm{g} \mathrm{L}^{-1}$ ) & 26,6 a & 23,2 c & $25,0 \mathrm{~b}$ & 24,9 & 9,09 & 0,00013 \\
\hline Taninos $\left(\mathrm{g} \mathrm{L}^{-1}\right)$ & $1,02 \mathrm{a}$ & $0,54 \mathrm{~b}$ & $0,61 \mathrm{~b}$ & 0,72 & 23,75 & 0,00001 \\
\hline Antocianinas (mg L ${ }^{-1}$ ) & 203,6 a & $140,5 \mathrm{~b}$ & $123,3 \mathrm{~b}$ & 155,8 & 22,12 & 0,00001 \\
\hline Prolina (mg L $\left.{ }^{-1}\right)$ & $66,7 \mathrm{~b}$ & $67,5 b$ & 93,4 a & 75,9 & 27,07 & 0,00015 \\
\hline Ácido tartárico (g L ${ }^{-1}$ ) & $4,8 \mathrm{~b}$ & $5,8 \mathrm{a}$ & $5,1 \mathrm{~b}$ & 5,2 & 11,94 & 0,00006 \\
\hline D0 420 nm & $0,205 \mathrm{a}$ & $0,148 \mathrm{~b}$ & $0,152 \mathrm{~b}$ & 0,169 & 25,30 & 0,00016 \\
\hline D0 520 nm & 0,388 a & $0,243 \mathrm{~b}$ & $0,236 \mathrm{~b}$ & 0,289 & 29,67 & 0,00001 \\
\hline Intensidade de cor (DO 420 + DO 520) & 0,592 a & $0,408 \mathrm{~b}$ & $0,415 \mathrm{~b}$ & 0,472 & 28,28 & 0,00008 \\
\hline Coloração (DO 420 / DO 520) & $0,536 \mathrm{~b}$ & 0,630 a & 0,646 a & 0,604 & 9,54 & 0,00001 \\
\hline Glicerol (g L $\left.{ }^{-1}\right)$ & $11,0 \mathrm{a}$ & $7,9 \mathrm{~b}$ & $7,4 \mathrm{~b}$ & 8,8 & 9,86 & 0,00001 \\
\hline Dióxido de enxofre total (mg L $\left.{ }^{-1}\right)$ & $28,2 \mathrm{~b}$ & $42,1 \mathrm{a}$ & $24,4 \mathrm{~b}$ & 31,6 & 20,41 & 0,00001 \\
\hline
\end{tabular}

Médias seguidas por letras distintas na linha diferem entre si pelo teste de Tukey a 5\% de probabilidade de erro.

2001 quanto à densidade, aos açúcares redutores, às cinzas, ao ácido tartárico e ao dióxido de enxofre total. Os resultados analíticos dos vinhos da safra de 2000 e 2001, em geral, evidenciaram um nível qualitativo inferior, devido às concentrações mais baixas de variáveis que determinam a estrutura, tais como o extrato seco, o extrato seco reduzido, os taninos e a cor dos vinhos, esta última expressa pelas antocianinas, a DO 520 e a intensidade de cor.

Quanto ao grau alcoólico do vinho, os valores obtidos estão de acordo com o potencial alcoólico do mosto, calculado a partir do teor de açúcar. Em relação ao pH, os valores detectados são baixos e conferem com aqueles indicados para os vinhos Isabel. $\mathrm{O}$ pH mais elevado no vinho da safra de 2001 deveuse, inicialmente, ao valor mais elevado do mosto nessa safra e, depois, ao equilíbrio iônico que ocorre entre o ácido tartárico e o K. O aumento da acidez total observada na passagem do mosto para o vinho é uma característica da vinificação da uva Isabel na Serra Gaúcha, devido à liberação dos ácidos orgânicos da película (RIZZON \& MIELE, 2002). Assim, o mosto de maior acidez total em 1999 também originou um vinho com acidez mais elevada; da mesma forma, em 2001, o mosto de menor acidez originou vinho menos ácido. Quanto à prolina, observou-se uma maior liberação da película por ocasião da maceração, pois constatou-se um aumento de seu teor no vinho em relação ao mosto.

Entre os fatores climáticos que participaram positivamente na qualidade do vinho da safra de 1999, estão a precipitação pluviométrica inferior à normal climatológica nos meses de janeiro, fevereiro e março (MANDELLI,1999) - período de maturação e colheita da uva Isabel - e o menor número de dias de chuva, o que também correspondeu à menor nebulosidade e, conseqüentemente, à maior insolação. Já na safra de 2000, observou-se um excesso de umidade nos meses de janeiro e março, maior número de dias de chuva e de nebulosidade e menor insolação (MANDELLI, 2000).

Em relação aos compostos voláteis (Tabela 4), detectou-se teor mais baixo de metanol nos vinhos da safra de 2000, o que provavelmente foi devido ao

Ciência Rural, v.36, n.3, mai-jun, 2006. 
Tabela 4 - Efeito da safra vitícola no teor de compostos voláteis do vinho Isabel na Serra Gaúcha.

\begin{tabular}{|c|c|c|c|c|c|c|}
\hline \multirow{2}{*}{ Variável (mg L $\left.{ }^{-1}\right)$} & \multicolumn{3}{|c|}{ Safra } & \multirow{2}{*}{ Média } & \multirow{2}{*}{ CV (\%) } & \multirow{2}{*}{ Prob $>F$} \\
\hline & 1999 & 2000 & 2001 & & & \\
\hline Acetato de etila & $54,0 \mathrm{ab}$ & $46,8 \mathrm{~b}$ & 59,9 a & 53,5 & 19,61 & 0,00085 \\
\hline Metanol & 304,5 a & $255,6 \mathrm{~b}$ & 311,5 a & 290,6 & 11,31 & 0,00001 \\
\hline 1-Propanol & 44,5 a & $20,9 \mathrm{~b}$ & $23,9 \mathrm{~b}$ & 29,8 & 50,22 & 0,00003 \\
\hline 2-Metil-1-propanol & $40,6 \mathrm{~b}$ & $37,0 \mathrm{~b}$ & 48,8 a & 42,1 & 13,35 & 0,00001 \\
\hline 2-Metil-1-butanol & 45,6 a & $40,8 \mathrm{~b}$ & $35,4 \mathrm{c}$ & 40,6 & 13,09 & 0,00001 \\
\hline 3-Metil-1-butanol & 180,0 a & $162,9 \mathrm{~b}$ & $122,8 \mathrm{c}$ & 155,2 & 11,83 & 0,00001 \\
\hline Soma dos álcoois superiores & 310,3 a & 261,5 b & 230,9 c & 267,6 & 8,80 & 0,00001 \\
\hline
\end{tabular}

Médias seguidas por letras distintas na linha diferem entre si pelo teste de Tukey a 5\% de probabilidade de erro.

menor teor de pectina na uva dessa safra. No entanto, mesmo que nenhum vinho tenha apresentado teor superior a 350 $\mathrm{mg} \mathrm{L}^{-1}$, máximo de metanol estabelecido pela Legislação Brasileira (BRASIL,1998), os teores registrados são elevados. Com relação aos álcoois superiores, em 1999, detectaram-se teores mais elevados de 1-propanol, 2-metil-1-butanol, 3-metil-1butanol e soma dos álcoois superiores. Isto provavelmente ocorreu devido aos teores de aminoácidos presentes na uva e às condições fermentativas do mosto. Considerando os aspectos qualitativos do vinho tinto, recomendam-se baixos teores de 1-propanol.

Quanto aos minerais (Tabela 5), em 2001, detectaram-se teores mais elevados de $\mathrm{Na}$, Fe e Zn. No caso do $\mathrm{Na}$, isso provavelmente foi devido às condições climáticas ocorridas no período de maturação e de colheita da uva (MANDELLI, 2001). No entanto, esses teores são baixos e correspondem àqueles indicados para vinhos dessa cultivar na Serra Gaúcha (RIZZON et al., 2000). No caso do Fe e do Zn, os níveis detectados são baixos e a variação observada nas safras vitícolas pode estar relacionada com a produtividade dos vinhedos e com as características do clima. Quanto ao Ca e ao Mg, mesmo que tenham mostrado variações com a safra vitícola, os teores são influenciados pelos tratamentos com calda bordalesa e pelas condições climáticas na maturação da uva. A safra vitícola não exerceu influência significativa no K, Mn, Cu e Rb do vinho Isabel.

\section{CONCLUSÕES}

A safra vitícola teve efeito significativo no peso do cacho e no peso da baga da uva Isabel, mas isso não ocorreu com a relação peso da ráquis/peso do cacho. No mosto, detectaram-se diferenças significativas em todas as variáveis, exceção à relação

Tabela 5 - Efeito da safra vitícola no teor de elementos minerais do vinho Isabel na Serra Gaúcha.

\begin{tabular}{|c|c|c|c|c|c|c|}
\hline \multirow{2}{*}{ Variável (mg L $\left.{ }^{-1}\right)$} & \multicolumn{3}{|c|}{ Safra } & \multirow{2}{*}{ Média } & \multirow{2}{*}{ CV (\%) } & \multirow{2}{*}{ Prob $>$ F. } \\
\hline & 1999 & 2000 & 2001 & & & \\
\hline $\mathrm{K}$ & $850,7 \mathrm{a}$ & $809,1 \mathrm{a}$ & $858,5 \mathrm{a}$ & 839,4 & 10,37 & 0,13736 \\
\hline $\mathrm{Na}$ & $2,41 \mathrm{~b}$ & $2,24 \mathrm{~b}$ & 3,70 a & 2,78 & 17,53 & 0,00001 \\
\hline $\mathrm{Ca}$ & $78,5 \mathrm{a}$ & $67,6 \mathrm{~b}$ & 73,6 ab & 73,2 & 13,31 & 0,00245 \\
\hline Mg & $79,9 \mathrm{~b}$ & $90,5 \mathrm{a}$ & 89,1 a & 86,5 & 11,84 & 0,00258 \\
\hline Mn & $1,55 \mathrm{a}$ & $1,60 \mathrm{a}$ & $1,49 \mathrm{a}$ & 1,54 & 31,93 & 0,78413 \\
\hline $\mathrm{Fe}$ & $1,43 \mathrm{~b}$ & $1,53 \mathrm{~b}$ & $1,78 \mathrm{a}$ & 1,58 & 20,83 & 0,00283 \\
\hline $\mathrm{Cu}$ & $0,16 \mathrm{a}$ & $0,18 \mathrm{a}$ & $0,15 \mathrm{a}$ & 0,16 & 37,56 & 0,32658 \\
\hline $\mathrm{Zn}$ & $0,32 \mathrm{c}$ & $0,44 \mathrm{~b}$ & 0,55 a & 0,44 & 26,50 & 0,00001 \\
\hline $\mathrm{Rb}$ & 5,85 a & 5,27 a & 5,94 a & 5,69 & 18,80 & 0,08517 \\
\hline $\mathrm{P}$ & $44,2 \mathrm{~b}$ & $60,5 \mathrm{a}$ & 68,6 a & 57,8 & 28,14 & 0,00011 \\
\hline
\end{tabular}

Médias seguidas por letras distintas na linha diferem entre si pelo teste de Tukey a 5\% de probabilidade de erro.

Ciência Rural, v.36, n.3, mai-jun, 2006. 
${ }^{\circ}$ Brix/acidez total. No vinho, houve diferença significativa nas variáveis clássicas e nas relacionadas aos compostos voláteis; quanto aos cátions, só não foi significativa para o K, Na, Cu e Rb. Em geral, a safra de 1999 foi melhor, pois apresentou parâmetros mais adequados de acidez total, extrato seco, extrato seco reduzido, alcalinidade das cinzas, taninos, antocianinas e glicerol, variáveis essas que determinam a estrutura e a cor dos vinhos, importantes fatores para sua qualidade.

\section{REFERÊNCIAS}

BRASIL. Ministério da Agricultura e do Abastecimento. Portaria n. 283, de 18 de junho de 1998. Diário Oficial da União, Brasília, Secção I, n. 106, 22 jun. 1998. Aprova normas e procedimentos para o registro de estabelecimento, bebidas e vinagres, inclusive vinhos e derivados da uva e do vinho e expedição dos respectivos certificados.

CHAMPAGNOL, F. Éléments de physiologie de la vigne et de viticulture générale. Montpellier: Déhan, 1984. 351p.

COOMBE, B.G.; MONK, P.R. Proline and abscisic acid content of the juice of ripe Riesling grape berries: effect of irrigation during harvest. American Journal of Enology and Viticulture, Davis, v.30, n.1, p.64-67, 1979.

MANDELLI, F. Comportamento meteorológico e sua influência na vindima de 1999 na Serra Gaúcha. Bento Gonçalves: Embrapa Uva e Vinho, 1999. 4p. (Comunicado Técnico, 34).

MANDELLI, F. Comportamento meteorológico e sua influência na vindima de 2000 na Serra Gaúcha. Bento Gonçalves: Embrapa Uva e Vinho, 2000. 4p. (Comunicado Técnico, 35).

MANDELLI, F. Comportamento meteorológico e sua influência na vindima de 2001 na Serra Gaúcha. Bento
Gonçalves: Embrapa Uva e Vinho, 2001. 4p. (Comunicado Técnico, 40).

MENEGUZZO, J. et al. Efeito da podridão do cacho na composição do mosto de Vitis vinifera cv. Gewürztraminer. Fitopatologia Brasileira, Brasília, v.24, n.1, p.45-48, 1999.

MIELE, A. et al. Free amino acids in Brazilian grape juices. Rivista di Viticoltura e di Enologia, Conegliano, v.43, n.4, p.15-21, 1990.

PERKIN-ELMER. Analytical methods for atomic absorption spectrophotometry. Singapura: Perkin-Elmer, 2000. 300p.

RIBÉREAU-GAYON, P.; STONESTREET, E. Dosage de tanins du vin rouge et détermination de leur structure. Chimie Analytique, Paris, v.48, n.4, p.188-196, 1966.

RIBÉREAU-GAYON, P.; STONESTREET, E. Le dosage des anthocyanes dans les vins rouges. Bulletin de la Société Chimique de France, Paris, v.9, n.419, p.2.649-2.652, 1965.

RIZZON, L.A. Características enológicas da safra vitícola de 1986. Jornal do Vinho, São Paulo, v.2, n.14, p.3, 1986.

RIZZON, L.A.; MIELE, A. A acidez na vinificação em tinto das uvas Isabel, Cabernet Sauvignon e Cabernet Franc. Ciência Rural, Santa Maria, v.32, n.3, p.511-515, 2002.

RIZZON, L.A. et al. Avaliação da uva cv. Isabel para a elaboração de vinho tinto. Ciência e Tecnologia de Alimentos, Campinas, v.20, n.1, p.115-121, 2000.

TEDESCO, M. et al. Análise de solo, plantas e outros materiais. Porto Alegre: Departamento de Solos, Faculdade de Agronomia, UFRGS, 1995. 174p. (Boletim Técnico, 5).

ZOECKLEIN, B.W. et al. Wine analysis and production. New York: Chapman \& Hall, 1994. 621p. 